\title{
Twelve generations of marginal protein deficiency
}

\author{
By R. J. C. STEWART, R. F. PREECE AND HILDA G. SHEPPARD \\ Department of Human Nutrition, \\ London School of Hygiene and Tropical Medicine, London WCIE $7 H T$
}

(Received Io fuly r974-Accepted I I September 1974)

\begin{abstract}
1. Colonies of rats have been maintained for twelve generations on diets adequate (dietaryprotein energy: total metabolizable energy (NDP:E) $O \cdot I$ ) or marginally deficient in protein (NDp:E 0.068).

2. In the malnourished colony, the proportion of 'small-for-gestational-age' offspring was ten times as high as amongst the well-nourished colony, growth was slow, sexual maturation delayed, especially in the females, and, when adult, both sexes were significantly lighter and shorter than adults of the well-nourished colony. Organs, other than the eye, weighed less than those of well-nourished 'age' controls, but when expressed relative to body-weight, the brain, pituitary, thyroid, adrenals, testes, thymus and eyes were larger, the pancreas unchanged and the kidneys smaller than those of the well-nourished 'age' controls. The relative weight of the liver showed little change, being slightly increased in the males and, like the ovaries, slightly reduced in the females. On a body-weight basis, the brains were about $50 \%$ heavier than normal, but in absolute terms were 5-5.5\% lighter than those of the wellnourished animals, the cerebellum (10.5\% lighter in males and $12.9 \%$ lighter in females) being more severely affected than the cerebrum ( $4 \%$ lighter).

3. The young malnourished rats showed increased exploratory activity, transient head tremors and an increased sensitivity to noise, the latter being long-lasting if not permanent. When adult, they showed marked differences in behaviour and learning patterns and it was difficult to attract and hold their attention. In situations demanding a choice the animals were very excited, emitted loud squeals and tried to escape from what was clearly a stressful situation. However, a casual examination of the malnourished adults revealed a rather small, badly groomed, excitable rat without gross abnormalities.

4. The findings are discussed in relation to changes found in malnourished human communities.
\end{abstract}

There are many reports (see review by Platt \& Stewart, I97x) indicating that protein-energy deficiency (PED) affects growth, development and reproduction as well as the chemical composition and morphology of many organs. Much effort has been expended on investigations into the effects of PED on brain development. The timing, duration and severity of the imposed deficiencies have varied greatly. Mothers have been maintained on inadequate supplies of food during gestation, the young have been given only limited access to the mother, the number of young suckled by one dam has been increased, animals have been given deficient diets only from weaning, and in some instances investigators have combined two or more of these techniques. Under any of these conditions the diet has to be severely restricted in quantity or quality, or both, in order to establish a deficiency during the critical periods of development. Except during periods of war or famine these are not the conditions existing in human communities in the depressed or non-industrialized areas of the world. More commonly the people exist on diets which, whilst limited in amount, are qualitatively suitable for adults, but are inadequate in both quantity and quality during pregnancy, lactation and growth (Gopalan \& Naidu, I972). 
Table 1. Composition of cubed diets $(\mathrm{kg})$

\begin{tabular}{|c|c|c|}
\hline NDp:E & $\begin{array}{c}A \\
0.068\end{array}$ & $\begin{array}{c}\text { B } \\
0.10\end{array}$ \\
\hline Oat flakes & $225^{\circ} 0$ & $225^{\circ} 0$ \\
\hline Casein & 10.0 & 110.0 \\
\hline Maize starch & $185^{\circ} 0$ & 85.0 \\
\hline Mineral mixture* & $25^{\circ} 0$ & $25 \cdot 0$ \\
\hline B-vitamin mixture $†$ & $5 \cdot 0$ & 5.0 \\
\hline Fat-soluble vitaminsf & 0.45 & 0.45 \\
\hline Fat & $50 \cdot 0$ & 50.0 \\
\hline Molasses & $25 \circ$ & 25.0 \\
\hline
\end{tabular}

NDP:E, dietary-protein energy: total metabolizable energy.

* Mineral mixture (g): $\mathrm{KH}_{2} \mathrm{PO}_{4}{ }_{15} 540 ; \mathrm{MgSO}_{4} 2290 ; \mathrm{CaCO}_{3}$ I $_{5240} ; \mathrm{FeSO}_{4} .7 \mathrm{H}_{2} \mathrm{O}$ 1080; $\mathrm{KI}$ 30; $\mathrm{MnSO}_{4} \cdot 4 \mathrm{H}_{2} \mathrm{O} 230 ; \mathrm{ZnCO}_{3} 20 ; \mathrm{CuSO}_{4} \cdot 5 \mathrm{H}_{2} \mathrm{O}$ I9; $\mathrm{CoCl}_{2} \mathrm{I} ; \mathrm{NaCl}_{1} 550$.

$\dagger \mathrm{B}$-vitamin mixture $(\mathrm{g})$ : thiamin $3^{\circ} 0^{\circ}$; riboflavin $10 \cdot 0$; pyridoxine $4^{\circ} \circ$; Ca pantothenate $60^{\circ} 0$; nicotinic acid $200 \cdot 0 ;$ myo-inositol $400 \cdot 0 ; p$-aminobenzoic acid 600.0; biotin 0.2 ; pteroylmonoglutamic acid 2.0 ; cyanocobalamin ( $\mathrm{I} \mathrm{mg/g}$ ) triturate 50.0 ; choline 1200.0; together with maize starch 7470.8 .

$\ddagger$ Fat-soluble vitamins: retinoyl acetate $3.44 \mathrm{~g}$; ergocalciferol $12.5 \mathrm{mg}$; menaphthone $2 \mathrm{~g}$; DL- $\alpha-$ tocopheryl acetate $2 \mathrm{~g}$; together with maize starch $900 \mathrm{~g}$.

An attempt to maintain a rat colony on a powdered diet with a net dietary-protein energy:total metabolizable energy ratio (NDP:E) of 0.05 , had to be abandoned. The combination of an expensive diet (much of which was spoiled by the rats) and a very high neonatal death-rate necessitating a large colony, which in turn led to a heavy demand for labour, proved to be financially prohibitive (Stewart \& Sheppard, I971). These difficulties were overcome by designing diets which could be fed as cubes and had protein values which were adequate (NDP:E O.IO) or only marginally deficient (NDP:E 0.068), thereby reducing food wastage and labour costs. Colonies have now been maintained on these diets for fifteen generations.

\section{EXPERIMENTAL}

\section{Diets}

Full details of the preparation of the cubed diets have been reported by Payne \& Stewart ( 1972) (Table I). For the first three generations all ingredients were purchased separately, weighed and mixed in the laboratory and sent away for cubing (Dixon \& Sons, Ware, Herts). We then began purchasing mineral and vitamin mixes which were made to our formula and in the batches of food used for generations 4 and 5 this proved to be satisfactory. A lower weight gain occurred in the 6 th and 7 th generations of both colonies and this was traced finally to gross errors in the composition of a commercially prepared batch of mineral mixture which apparently rendered the diet less palatable. Unfortunately, tracing this fault, purchasing fresh ingredients and preparing and cubing another batch of diet took 6-8 weeks, by which time most rats were failing to gain weight and some of the older animals, especially in colony B (high-protein diet), were actually losing weight. This situation continued for some weeks after the fresh laboratory-prepared diet was offered and the effect spread into later generations. The mineral and vitamin mixtures are now prepared 
by Cooper Nutrition Products Ltd (Stepfields, Witham, Essex), who analyse each batch of mineral mixture before delivery.

\section{Animals and management}

Litters of black-and-white hooded rats from the same stock and maintained under the same conditions as those used earlier (Stewart \& Sheppard, 1971) were divided into two matched groups at 3 weeks of age. One group (colony A) was given the diet of low protein value (marginally deficient, NDp:E 0.068 , diet A; Table I) and the other (colony B) was given a diet of high protein value (adequate, NDP:E O.IO, diet B; Table I). This procedure was repeated twice at 3 -monthly intervals, so that at any time there were animals of two or three different generations available for observation and testing, thus the salt mixture episode, although occurring over a limited period, affected more than one generation.

The animal rooms were maintained at $24^{\circ}$ and the rats were housed in groups of three in plastic-sided cages, the floors and tops of which were made of stainless-steel mesh (type $\mathrm{RB}_{3}$; North Kent Plastic Cages Ltd, Dartford, Kent). Pregnant and lactating rats were housed singly in cages of a similar type but with solid plastic floors. In these solid-floor cages plenty of sawdust and wood-wool for nest building was available. The top of each cage incorporated a food hopper which always contained an ample supply of cubed diet. Fresh water was available at all times. There was adequate daylight during the summer months and this was supplemented during the winter so that the animals never had more than $12 \mathrm{~h}$ of darkness/d.

\section{Methods}

Females used for breeding were mated at 3 months of age to males of their own dietary group and the young were weaned at 4 weeks of age onto diets similar to those eaten by their parents. Gestation times were usually calculated from the appearance of a mating plug, but on other occasions male rats were only left with the females for $16 \mathrm{~h}$. All animals were weighed at least once per week and, except at weekends, pregnant rats were weighed daily from the 14 th day of gestation. Offspring and mothers were weighed as soon as possible after parturition, and young born outside laboratory hours or not weighed before being suckled were not included when calculating birth weights and litter sizes. The body-weights of the mother during the three weeks before, and the six weeks after parturition were excluded from Table 3 and Fig. 2. In some litters the times of opening for the eyes and vaginal canals were recorded, as was the descent of the testes. These records were made early in the morning, irrespective of the time of birth.

The animals were seen every day and examined more thoroughly once per week when notes of agility, gait and general behaviour were made, together with some tests of their reaction to noise and strange situations. Some body-fluids were collected for biochemical tests which will be reported by Dr C. R. C. Heard. Of the many behavioural tests attempted only those relating to noise or to visual discrimination using the Lashley (1938) jumping platform under conditions defined by Turkewitz (1974) were thought to be useful. 
Eight to ten male and female rats of each generation of both colonies were killed at 6 months of age; some samples were obtained also at birth, I and 3 months, but this report deals mainly with the older animals. The females killed at 6 months of age had been mated 3 months earlier and many of them had produced and reared a litter; in this way we were able to economize on animal-house space. No deliberate selection for breeding or killing was attempted. The rats were anaesthetized with chloroform and a cannula was inserted into the left ventricle of the heart and the right auricle was opened. The body was perfused with normal saline and then with buffered formalin at a pressure of $3030 \mathrm{~N} / \mathrm{m}^{2}$. The latter contained a trace of toluidine blue so that the efficiency of the perfusion could be seen. Measurements of body size were made on the formalin-fixed, but otherwise intact, animal; these were anus to nose $(a)$, occipital crest to nose $(b)$ and occipital crest to posterior aspect of the eye $(c)$. Face length was obtained by subtracting $c$ from $b$. The femur was measured after its removal from the body.

The skull was opened to expose the brain and the head was stored in formalin for at least $2 \mathrm{~d}$. The brain was then removed and weighed in three portions: $(a)$ the cerebrum (forebrain plus midbrain), $(b)$ the cerebellum and $(c)$ the pons plus medulla oblongata. The endocrine glands, liver, kidneys and thymus from two male and two female rats of each generation of both colonies were weighed and, with the brains and spinal cords, stored for histological examination.

To simplify the presentation of body-weight increases, generations have been grouped for that purpose as follows: $1-3$, for which all the food was mixed in the laboratory; 4 and 5 , for which the commercially prepared mixtures were satisfactory; 6 and 7 , for which the mineral mixture was known to be incorrect; 8 and 9 , which continued to show some effects of the 'mineral-mixture' episode and 10-12, in which these effects seemed to have disappeared, at least in the well-nourished colony.

\section{RESULTS}

\section{Birth weights}

Individual birth weights varied greatly, from 2.8 to $6.0 \mathrm{~g}$ in the rats receiving the marginally-protein-deficient diet (colony A) and from 3.8 to $7.0 \mathrm{~g}$ in those given the adequate-protein diet (colony $B$ ), with mean values of 4.7 and $5.4 \mathrm{~g}$ respectively. This difference was highly significant $(P<0.001)$. Variations in birth weight were not related to gestation times which were similar for both colonies. The alterations observed in successive generations of the two colonies are shown in Table 2 . The lower birth weights recorded for generations 8-ro of colony B and 7 and 8 of colony A appeared to be related to the smaller size of the mothers (Table 3 ) whose growth coincided with the period when the mineral mixture was incorrect and food intakes were low. The newborn were considered to be 'small-for-gestational-age' (SFGA) if, at full term, their weight was $4.2 \mathrm{~g}$ or less. Using this criterion, the proportion of the SFGA young was greater for each generation of rats of colony A (malnourished) than for the corresponding generation of colony B (well-nourished) (Table 2) and the value for the whole of colony $\mathrm{A}(27 \%)$ was about ten times that of colony $\mathrm{B}$ (Table 4 ). 


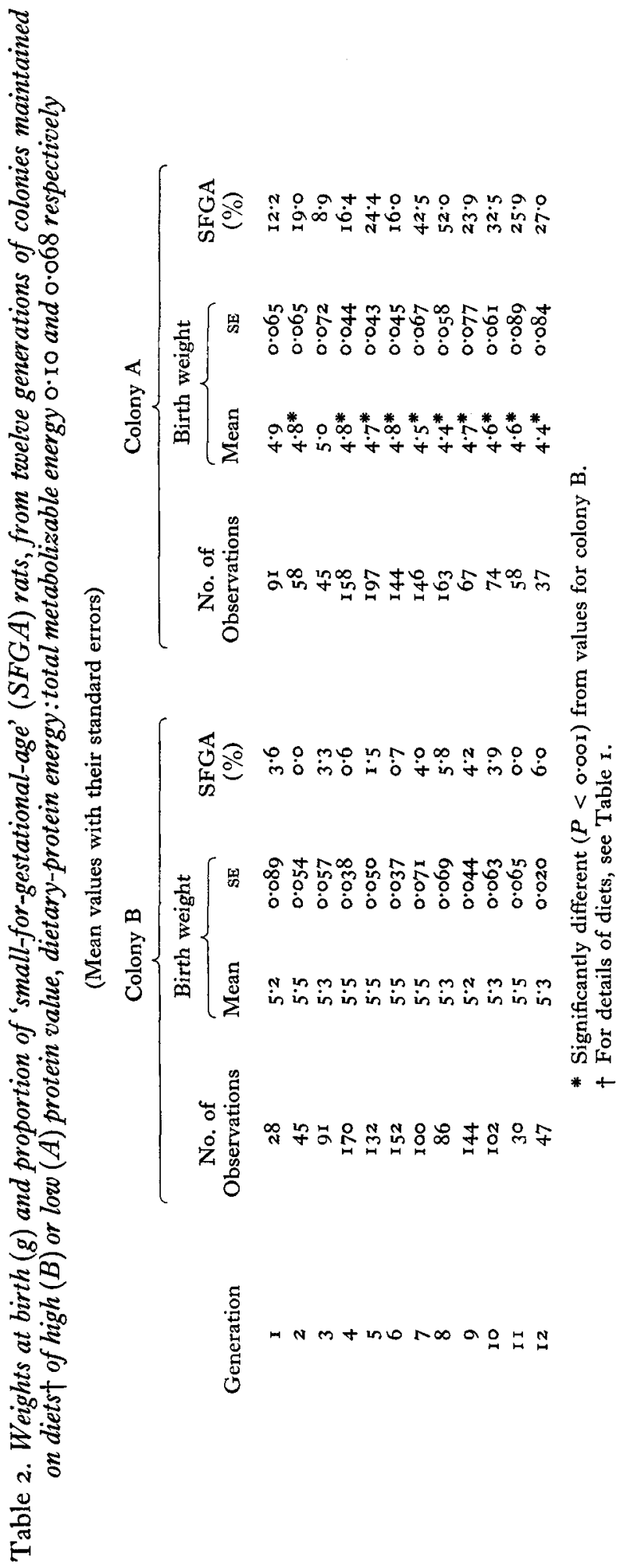


Table 4. No./litter, weights of litter and individuals ( $g$ ), and proportion of 'small-forgestational-age' (SFGA) rats born into colonies maintained for twelve generations on diets $\uparrow$ of high $(B)$ and low $(A)$ protein value, dietary-protein energy: total metabolizable energy 0.10 and 0.068 respectively.

(Mean values with their standard errors)

\begin{tabular}{|c|c|c|c|c|c|c|}
\hline & \multicolumn{3}{|c|}{ Colony B } & \multicolumn{3}{|c|}{ Colony A } \\
\hline & $\begin{array}{c}\text { No. of } \\
\text { observations }\end{array}$ & Mean & $\mathrm{SE}$ & $\begin{array}{c}\text { No. of } \\
\text { observations }\end{array}$ & Mean & SE \\
\hline No./litter & 105 & $10 \cdot 75$ & 0.3 & 143 & $8 \cdot 6 *$ & 0.2 \\
\hline Litter weight & 97 & $58 \cdot 3$ & $1 \cdot 56$ & I 43 & $39 \cdot 8 *$ & 0.09 \\
\hline Individual weight & I 127 & $5 \cdot 4$ & 0.019 & 1238 & $4.66^{*}$ & 0.019 \\
\hline SFGA (\%) & 1127 & $2 \cdot 8$ & & 1238 & 27 & \\
\hline
\end{tabular}

* Significantly different $(P<0.001)$ from values of colony $\mathrm{B}$.

+ For details of diets, see Table $\mathbf{r}$.

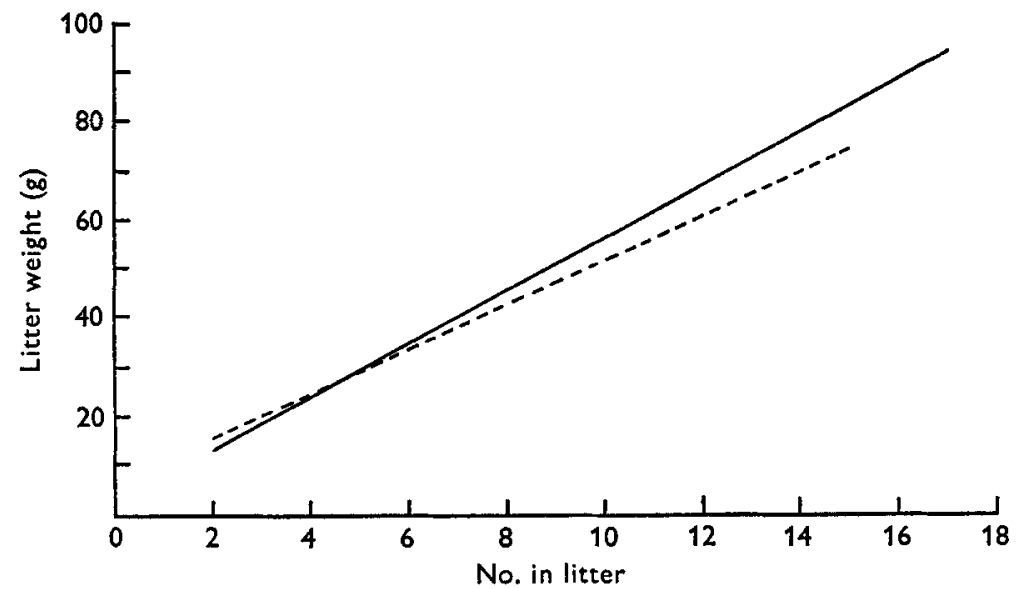

Fig. 1. Regression lines of litter weight $v$. no. in litter for rats from colonies maintained for twelve generations on diets of high (B) (-) and low (A) (---) protein value, dietary-protein energy:total metabolizable energy $O^{\circ} \mathrm{I} O$ and 0.068 respectively. Colony A, slope 4.019, intercept 6.694; colony B, slope $5 \cdot 156$, intercept 2.822. (From Stewart, 1973.)

Many of the SFGA young died before weaning and undoubtedly were mainly responsible for the large number of early deaths ( $48 \%$ of the live born) in the malnourished colony. Mean litter weights were reduced in the malnourished colony to $39.8 \mathrm{~g}$, that is $18.5 \mathrm{~g}$ less than the value for the well-nourished colony (Table 4 ). Part of the deficit can be related to the lower litter number, 8.6 for colony A, 10.75 for colony B. However, as is shown in Fig. I, except when the mother produced less than five pups, litter weights were lower in colony A than in litters of equal number from colony B. The weight discrepancies increased with increasing litter size.

\section{Growth after birth}

Rats born of malnourished mothers grew slowly and were not suitable for weaning before $28 \mathrm{~d}$ of age. At this time their mean weight was $27 \mathrm{~g}$, only about $50 \%$ of that of the normal rats $(62-65 \mathrm{~g})$. Although active and apparently searching for food, these 


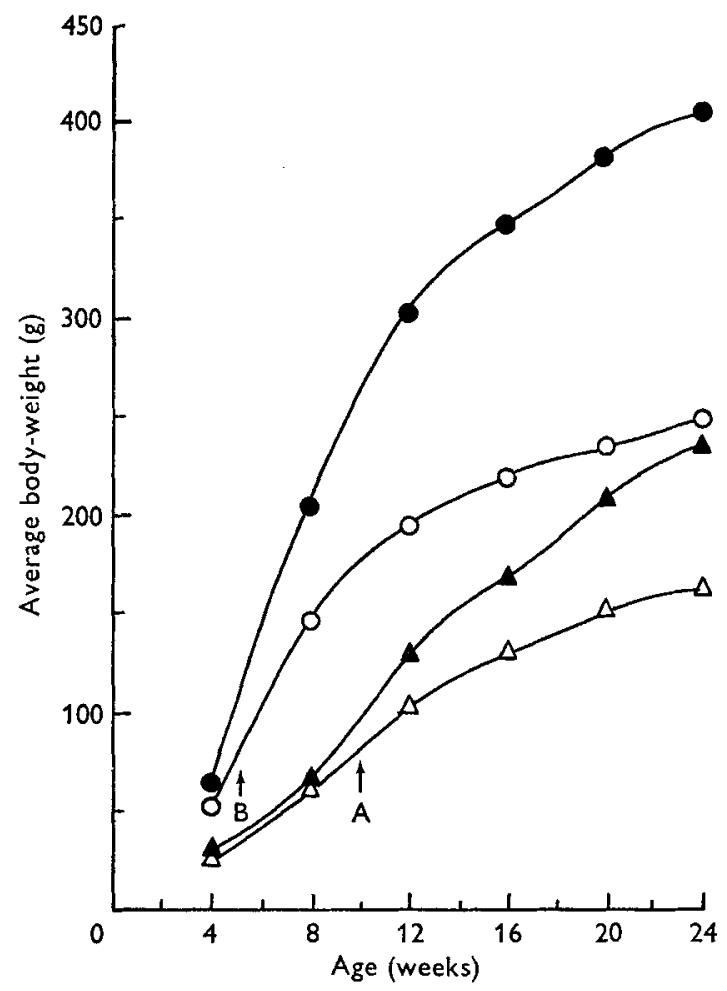

Fig. 2. Weight curves for male and female rats from colonies maintained for twelve generations on diets of high (B) and low (A) protein values, dietary-protein energy: total metabolizable energy 0.10 and 0.068 respectively. $\Delta$, Males of colony $A, O$, colony $B ; \triangle$, females of colony $A, O$, colony $B$; $\uparrow$, times at which vaginal opening was first noted in generations I I and 12 .

malnourished rats did not show as much interest in their food as the larger, wellnourished animals.

In the first 2--3 weeks after weaning, animals from the malnourished colony showed weight increases, which varied greatly and were often very small. For example, one 42 -d-old rat from colony A (Plate $\mathrm{I}$ ) weighed only $\mathrm{r} 8 \mathrm{~g}$, the same as a $\mathrm{r} 2$-d-old rat from colony $B$ and only one-fifth as much as a well-nourished 'age' control.

Combined curves for mean weights $v$. age of the twelve generations of each colony are shown in Fig. 2; at 24 weeks of age the malnourished males weighed only $59 \%$ and the females $67 \%$ of the weight of the well-nourished controls.

Table 3 shows the mean weights-for-age for the different generational groups. Rats offered the less palatable diets (generations 6 and 7) had lower body-weights than those of generations 4 and 5 . The extent of the differences was $15 \%$ for the males and $8 \%$ for the females of colony $\mathrm{B}$ and $25 \%$ and $14 \%$ respectively for colony $\mathrm{A}$. The small mothers produced many SFGA but full-term young and the 'mineralmixture' effects continued into later generations. In colony $\mathrm{B}$ an improvement was found when the diet was corrected and from generation ro onwards there were no residual effects on weight. However, in colony A there was little change, for either 
Table 5. Day of eye opening in rats born into colonies maintained for twelve generations on diets $\dagger$ of high $(B)$ and low $(A)$ protein value, dietary-protein energy:total metabolizable energy 0.10 and 0.068 respectively

\begin{tabular}{|c|c|c|}
\hline \multirow{2}{*}{$\begin{array}{l}\text { Age } \\
\text { (d) }\end{array}$} & \multicolumn{2}{|c|}{ No. opening } \\
\hline & Colony B & Colony A \\
\hline I I & $\mathbf{I}$ & 0 \\
\hline 12 & 7 & 0 \\
\hline 13 & 33 & 10 \\
\hline 14 & 43 & 33 \\
\hline 15 & 7 & 32 \\
\hline 16 & 2 & 9 \\
\hline I7 & 0 & 3 \\
\hline 18 & 0 & 5 \\
\hline 19 & 0 & I \\
\hline Mean age (d) & $13.6 \pm 0.09$ & $14.8^{*} \pm 0.13$ \\
\hline
\end{tabular}

sex, in generations 8 and 9 and the mean weights at 24 weeks for generations 10-12 were still less than those for generations 4 and 5 .

Small but significant differences between the colonies $(P<0.00 \mathrm{I})$ were observed in eye-opening times, colony $A$ averaging $14.8 \mathrm{~d}$ with a range of $13^{-19} \mathrm{~d}$ and colony B I $3.6 \mathrm{~d}$ with a range of I $-\mathrm{I} 6 \mathrm{~d}$ (Table 5 ). Sexual development also was delayed in colony A. The stock animals would breed at 8 or 9 weeks of age, but as it was realized that colony A animals might develop more slowly than the controls, no animals were mated before 13 weeks of age. This was successful for ten generations. Animals of the I I th and I2th generations of colony B mated without difficulty at $\mathrm{I}_{3}$ weeks and the sexes had to be separated by 6 weeks of age to avoid unwanted pregnancies. Rats from colony A often failed to conceive before the I 4 th or I6th week, so that a marked delay in sexual maturation had developed. The vaginal canals of some animals of colony $B$ were patent as early as $35 \mathrm{~d}$ and all were open by $50 \mathrm{~d}$, whereas in the later generations of the malnourished group it was rare for the canal to become patent before the

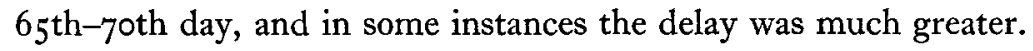

In each generation a proportion of the malnourished females used for breeding appeared to be unable to produce milk: their mammary glands showed little or no sign of activity (macroscopic examination), their litters died and the stomachs and intestines of the young showed no evidence of milk ingestion. This was particularly evident in generations 6 and 7 . Even in animals which reared their young the mammary glands were underdeveloped (Plate $2 f, g$ ) and the milk supply was low. Typical weights of the whole of the mammary tissue of rats $28 \mathrm{~d}$ post-partum and $3 \mathrm{~h}$ after being separated from their litters were $4.9 \mathrm{~g}$ for colony A and $15.7 \mathrm{~g}$ for colony $\mathrm{B}$.

Parturition appeared to be no more difficult or prolonged in the malnourished than in the well-nourished rats and the young were usually efficiently cleaned. Rather more of the malnourished mothers ignored their young and occasionally some human assistance was required in nest building. The malnourished mother tended to desert 


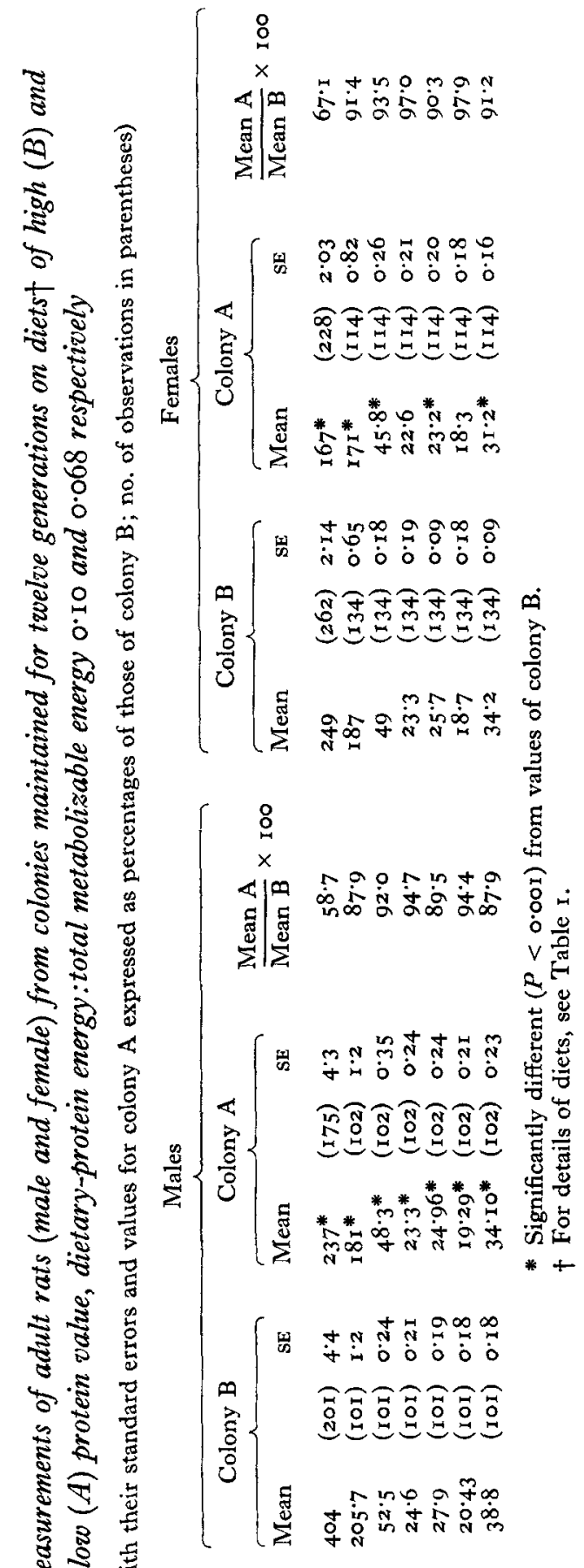

है

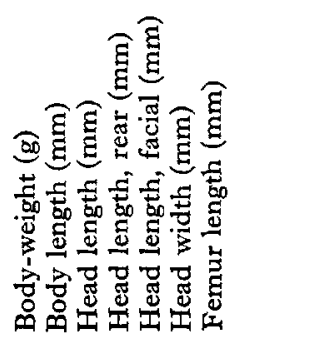


Vol. 33

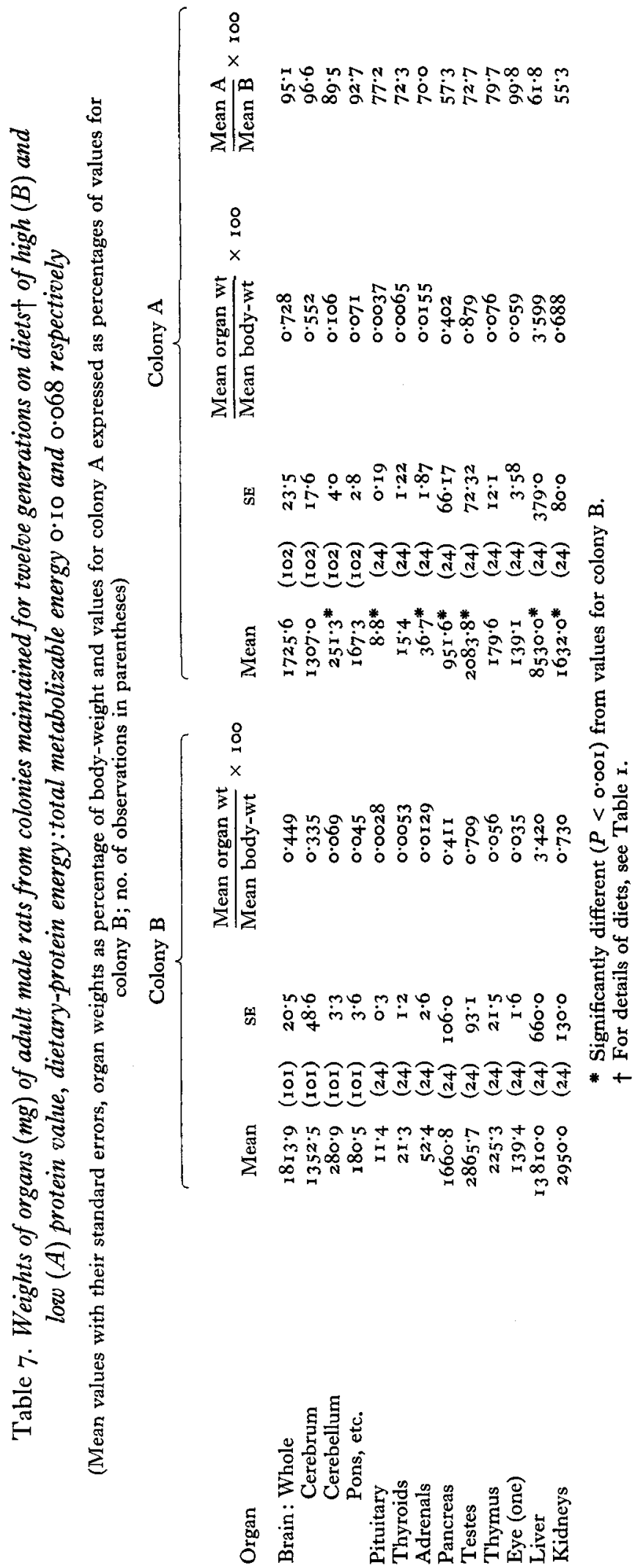


244 R. J. C. Stewart, R. F. Preece and Hilda G. Sheppard 1975

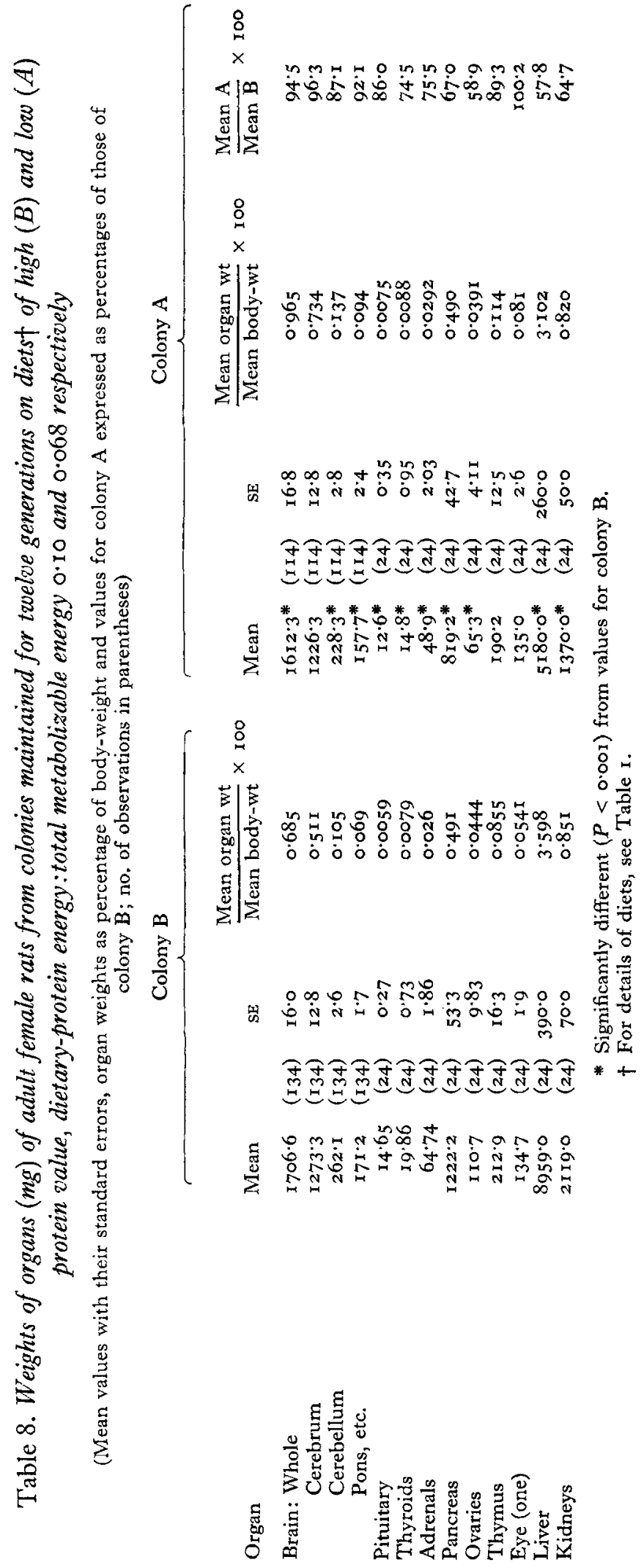


the nest more readily than did the well-nourished dam and, if the young escaped to, or were removed to, a remote part of the cage, the mother was less prompt in retrieval. Although many of the malnourished young disappeared, some bodies were found and it would seem that the mothers ate dead animals and did not usually kill and eat. Occasionally a cage would be found in which there was blood on the walls, the nest destroyed, the young mutilated and the mother in a very distressed, nervous condition. These outbursts usually occurred at night and never when observers were present. The well-nourished colony was not involved. Noise was a possible cause, for the results of three such episodes were found the morning following a nearby explosion (bombing of the Post Office Tower), but loud daytime noises, such as thunder, did not cause similar reactions. A full report of maternal performance and behaviour is in preparation.

The animals were regarded as adult at 24-26 weeks of age and very few were allowed to live beyond this time. There were great differences in body size. Table 6 shows mean values for body measurements of the adult male and female rats of the two colonies, as well as the values for colony A expressed as percentages of those for colony B. Although all the values for colony A were low, they were not uniformly so. Males were more severely affected than females, and body-weight (4I\% lower for males from colony $\mathrm{A}$ and $33 \%$ lower for females) was more affected than body length (12 \% lower for males from colony A and $8 \%$ lower for females). Percentage reductions in body and femur lengths were similar, but the over-all head length was less markedly affected. Most of the differences found in the lengths of the heads could be attributed to the size of the facial bones and this also led to changes in the shape of the head and to an altered appearance of the eyes (Plate $2 d$ and $e$, Table 6).

Differences between the colonies, in organ weights, varied greatly and Tables 7 and 8 show the mean organ weights, mean organ weights as percentages of mean bodyweight, and the mean organ weights of colony $A$ as percentages of those of colony $B$.

Except for the eyes, all the organs of colony $A$ rats weighed less than those of rats from colony $\mathbf{B}$, but in most instances the organ weights represented a greater proportion of the total body-weight. Exceptions in both sexes were the pancreas and kidneys, the former being equally as retarded as the body-weight and the latter was more retarded, whilst in the females, but not the males, the liver and gonads were also more severely affected. The eyes and the central nervous system were the least affected and, when expressed as percentages of body-weight, values were much higher than those of colony $B$.

\section{Appearance and behaviour}

The young of the malnourished mothers were very active, and $2,4 \mathrm{~h}$ after birth were making more vigorous and successful attempts to crawl than the young from the well-nourished colony. This enhanced exploratory activity continued in those animals which survived to weaning. Those which died suffered a period of reduced activity during which they were apathetic, made little effort at sucking even when placed at the mother's teats, and finally passed into a moribund state. Before reaching this advanced stage these animals often developed marked tremors of the head which did not appear to be related to temperature and which could easily be felt when the 
animal was held in the hand. Although head tremors occurred, they were less common amongst the stronger surviving members and were rarely seen after the age of 4 weeks. Such 'attacks' appeared to be initiated by noise or other disturbances and were elicited more easily early in the day (08.30 to ro.oo hours). They were not seen in the control colony which, during the first 4 weeks, spent more of the daylight hours within the nest and always appeared to be gorged with food. Malnutrition delayed the development of the hair, the rats had thin coats with many sparse or bald patches at a time when a full coat should have developed. Plate $2(a)$ shows a malnourished rat in which very little fur had developed by io $\mathrm{d}$ of age. When developed, the hair usually appeared to be sparse, fine and easily shed, and the sides of the face which were rubbed along the feeding hoppers were often bald (Plate $2 c$ ). By 6 months of age the hair was coarse and encrusted with many more particles of debris and desquamated skin than that of the well-nourished rats. The colour of the hair was also affected; usually the black became grey, but in some instances it was a distinct brownish colour. These changes in colour gradually disappeared and were rarely seen in males after 4-6 months of age, or after that time in females not used for reproduction. However, it was at this stage that the white hair of the malnourished rats developed a yellow coloration which is usually associated with age. This yellowing developed later in the well-nourished rats. After weaning, the malnourished animals remained alert and showed jerky, faster and less predictable movements than did the controls, so that if the tops of the cages were removed the malnourished groups were the more difficult to restrain. The animals had a characteristic gait in which the thin, spindly hind legs were more extended than normal and were used in a hopping manner. These jerky, lively movements had to be differentiated from size effects, for clearly the wellnourished group could overcome larger obstacles and were better able to stand on their hind legs and jump than the malnourished rats of similar age. The eyes of the malnourished animals appeared large and prominent (Plate $2 d, e$ ), but no differences in weight or diameter were found (Tables 7,8 ).

The animals of both colonies reacted similarly to light, even when this was of varying intensity. Noise, however, was useful in differentiating between the colonies. Members of colony $\mathbf{B}$ reacted to snapping of the fingers or a gentle clap by first being startled and then by investigating, when they tried to determine the source of the noise and, having done this, they proceeded with their feeding or grooming. Malnourished animals reacted more violently, often jumping so that all four feet left the floor and there was little attempt at investigation. Although rats of both colonies reacted to an auditory stimulus when it was first applied, and sometimes when it was applied for the second or third time, repetition finally stopped the response from the well-nourished animals, but the malnourished rats continued to react, being startled and apprehensive, but not still investigating even after ten or twenty stimulations. This over-reaction to noise developed at differing ages, occasionally before weaning, but, once developed, was usually permanent (up to 6 months of age). As slight sounds were so effective in differentiating between the groups, attempts were made to utilize the production of audiogenic seizures as a further test. Although it appeared that a higher proportion of the malnourished animals developed such seizures, no 
level of stimulation was found which induced fits in members of colony A without also affecting some members of colony $\mathrm{B}$.

Numerous techniques were used to test discrimination and learning but a modification of the Lashley jumping-platform procedure was found to have fewest disadvantages. In a preliminary investigation (Turkewitz, 1974) with three visual discrimination tests, the malnourished animals performed as well as the wellnourished animals in test $\mathrm{I}$, were slightly different in test 2 and markedly different in test 3 . The cumulative effect was that $84 \%$ of the well-nourished rats completed the three tests, but only $40 \%$ of the malnourished animals were successful. When presented with situations needing a decision, the malnourished animals often became very excited; for example, when placed on the raised starting platform of the Lashley apparatus the stock and colony B animals would examine the two doors, make a decision and jump or lunge across. In contrast, the malnourished animals spent more time on the starting platform. They stretched forward first towards one door and then the other, oscillating between these positions in a jerky, bird-like manner and becoming very excited before making a choice. Following a series of wrong choices, the malnourished animals would turn away from the doors, and emit loud squeals before attempting to jump or fall off the starting platform. Others would try to leap over or between the doors, probably to avoid making any decision. Some animals fell many times whilst trying to climb down from the platform (Plate $2 h$ ). In contrast, most of the well-nourished rats, even after making errors, still examined the doors and made a choice without becoming excited.

\section{DISCUSSION}

There have been complications during the 9 years of the experiment. The animals had to be transferred from a field station to the London School of Hygiene and Tropical Medicine (generations 4 and 5 ), there was a self-imposed dietary restriction (generations 6 and 7), and a further move to the Clinical Nutrition and Metabolism Unit (generations 9 and ro). These transfers led to minor alterations in absolute values of, for instance, birth and adult weights in different generations (Stewart, 1972, 1973), but for each generation there have been significant differences between the colonies.

Mean litter weights within the malnourished colony were $32 \%$ less than those of the controls. Part of the difference can be related to the $20 \%$ reduction in the average number of young and the rest to a low mean birth-weight for the individual offspring. The reduced number of young was expected, after the report of Gupta \& Christie (1968), that protein deficiency (NDP:E $0 \cdot 05$ ) led to a reduction in both the number of ova released and the number of successful implantations. The low individual birth weights are contrary to the findings of Naismith, who reported that by utilizing their own tissues (Naismith, 1969) and modifying metabolic processes (Naismith \& Ritchie, 1973), mothers were able to protect their young from intra-uterine malnutrition. Naismith used diets with a protein value similar to that of our diet A, but whereas his rat mothers were only malnourished during and immediately prior to pregnancy, 
rats of colony A were malnourished throughout their existence. It appears, therefore, that whilst a well-developed mother can use some of her own tissues to protect the young, a stage is reached at which this is no longer possible and the deficiencies are then shared by mother and offspring. This would be consistent with the apparently contradictory reports from Holland (Smith, 1947) and Russia (Antonov, 1947) about the effects on women of dietary deficiencies during World War Two.

The depression of birth weight in the first generations was similar to that reported by other workers using protein-deficient diets (Chandran \& Ambegaokar, I959; Gupta, 1969) and rather less than when the energy intake of the mothers was restricted by $50 \%$ (Chow \& Lee, 1964). Later generations showed slightly greater changes especially when, in generations 6 and 7 , energy restriction was superimposed on the protein deficiency. Whether the low birth weight in generations ro-12 of colony A should be related to the period of energy restriction or whether it is the cumulative effect of continuing inter-generation malnutrition is not known, but in generations ${ }_{13}$ I $_{5}$ (not reported here) there has been neither improvement nor further decline in the birth weights of colony $\mathrm{A}$. It seems likely therefore that the colony is now relatively stable. The well-nourished animals showed a slight increase in birth weight when transferred from the stock ration (mean birth weight $5.25 \mathrm{~g}$ ) to diet $\mathrm{B}$ (mean birth weight $5.4 \mathrm{~g}$ ) and this was maintained from generation 2 until generation 7 . This increase in birth weight of the offspring of animals transferred from a diet with NDP:E about 0.09 to one of NDP:E O.10 was unexpected; the diets, however, varied in more than protein, and other factors such as minerals and vitamins may have been involved. In generations 6 and 7 the importance of the acceptability of the diet was also noted, with alterations in the mineral mixture leading to a self-imposed dietary restriction, small adult size and low birth weights. These responses to small (from stock diet to diet B) and larger (faulty mineral mixture) dietary changes emphasize the care needed when comparing results from different institutions. The slow recovery of the rats of colony $B$ from the effects of dietary restriction was surprising, but the low birth weight for generation 12 is probably due to one very large litter containing all the SFGA young in that relatively small group. Generations $\mathrm{I}_{3}-\mathrm{I}_{5}$ have reverted, as did generation I $\mathrm{I}$, to the $5.5 \mathrm{~g}$ standard.

The reduction in average birth weights for colony $A$, although highly significant $(P<0.001)$, was only $14 \%$. The young were not equally affected and the prime reason for the average reduction was a tenfold increase in the proportion of SFGA offspring. Young were considered to be SFGA when their birth weight was $4.2 \mathrm{~g}$ or less (mean $-2 \mathrm{SD}$, for colony $\mathrm{A}=4.124 \mathrm{~g}$ ). The use of this value for both colonies can be justified for two reasons: (I) the original members of the colonies were littermates from a stock which had shown minimal size variations $(5 \cdot 2-5 \cdot 3 \mathrm{~g})$ over many generations, and (2) when roth generation mothers of colony A were rehabilitated from the I $4^{\text {th }}$ day of pregnancy, their offspring were of near-normal weight at birth $(5.3 \mathrm{~g})$ and, if well-nourished until 6 months of age, were at least as large as the controls, indicating that selection for size during the ten generations was not a major problem (Stewart, Preece \& Sheppard, I973a). However, the physically rehabilitated animals were not normal with respect to behaviour (Stewart, Preece \& Sheppard, 
1973b). Many of the SFGA offspring died, but there was no evidence that SFGA pups of colony A suffered a higher mortality rate than did those of colony $B$, and in fact small pups of generations 10-12 of colony A appeared to have a better chance of surviving than did those of similar weight born into generations 4-7 of colony A and 10-12 of colony B. Animals in colony A suffered a further disadvantage in that the mammary development of their mothers was always poor and it was not surprising that during the suckling period growth was slow. The transient head tremors occurred only in colony A rats and usually in the most retarded animals. These poorly controlled movements, as in the dog (Platt \& Stewart, 1968, 1969), were probably due to delays in the maturation of the central nervous system (Stewart, Merat \& Dickerson, 1974). Delayed dendritic development has been described in protein-energy deficient rats (Eayrs \& Horn, 1955; Cragg, 1972).

The increased exploratory activity during the first 4 weeks was at first thought to be a searching for more or better-quality food, but the rather aimless wanderings occurred when the animals and their mothers were transferred to the high-protein $\operatorname{diet}(\mathrm{B})$. As the malnourished animals reacted more vigorously to noise than did the well-nourished, it may be that they were very sensitive to normal animal-house noises and that this stimulated the wandering and fearfulness. Alternatively, it could be an inability to concentrate, exemplified by the difficulty of attracting, and even more of holding, their attention. An inability to concentrate their attention would also explain the behaviour during the visual discrimination tests.

The differentiation between the bones of the cranium and those of the jaw, femur and pelvis is another example of the restricted, but balanced, growth of the central nervous system and the surrounding bone in animals given a protein-deficient diet containing sufficient vitamin A (see Stewart, 1965). If the cranial bones had been restricted to the same extent as other bones then pressure on the nearly full-size brain (95\% of normal) would have been considerable. The vertebral canal was slightly smaller than in the well-nourished animals, but many searches failed to reveal any evidence of direct pressure on the spinal cord.

Most organs, although small, were larger than normal when related to body-weight, the exceptions being the pancreas, which is known to be severely affected by PED, and, more surprisingly, the kidneys. The eye was the only organ weighed which did not appear to be affected. The cerebellum (10.5\% smaller in males from colony A and $12.9 \%$ smaller in females) was more severely affected than the cerebrum $(4 \%$ smaller in colony A rats) and in 6-month-old animals these changes must be regarded as permanent and not merely delays in development. Slight reductions in the absolute amounts of DNA were found at birth (A. Merat, personal communication) and at 6 months of age (M. Rahman, personal communication) but the concentrations were not reduced.

Physically males were more severely affected than females, but there were no obvious sex differences in exploratory behaviour, response to noise or visual discrimination. The malnourished males which had altered behaviour and learning patterns had lower body-weights (5\% lower) and larger brains $(\mathrm{I} \cdot \mathrm{I} \%$ larger) containing as much DNA as those of the normal, well-nourished females, indicating that 
less attention should probably be paid to brain size and cell number and more to factors such as dendritic development, amount and type of protein within the cell, enzymes and hormonal balance. It should be recognized, however, that while the total brain of the malnourished male weighs $\mathrm{I} \cdot \mathrm{I} \%$ more than that of the well-nourished female, this apparent equality is brought about by a heavier cerebrum $(2 \cdot 6 \%$ heavier $)$ and a lighter cerebellum (4.1\% lighter). On a casual examination the adult animals of colony A would be regarded as small, badly groomed, nervous and excitable, but not obviously abnormal. Only when subjected to some form of stress do the alterations in behaviour become manifest.

Great care has to be exercised when extrapolating from animal experiments to man. One great barrier has been the inter-species variations in the rates and timing, and therefore susceptibility to nutritional stress, of the cellular development of the brain. Dobbing (1974) argued that 'brain cell number is no necessary index of intellectual, excellence, any more than is brain size within the reasonable limits of normal distribution'. Earlier, he had stated that 'at least five-sixths of the human brain growth spurt is postnatal and in this respect humans resemble rats much more closely than was formerly thought' (Dobbing \& Sands, 1973). These statements and the results of the present experiments indicate that it may be more profitable to examine the similarities between malnourished human and animal communities rather than the factors which separate them.

Dietary deficiencies among deprived peoples have been related to ignorance and habit, and certainly traditional or religious taboos, or both, are important as they usually affect the mother and young, but there seems no reason to doubt 'that a people eats a good diet when it can be afforded' (Milam \& Darby, r945). Those born into low socio-economic groups may eat a poor-quality diet throughout their lives, and the incidence of infections (Scrimshaw, 1964) and periods of restricted energy intake will each act synergistically to reduce further the protein value of the diet to the consumer (Platt, Miller \& Payne, 196r). It is amongst such groups that low birth weights and high neonatal losses occur. The low average birth weights are brought about primarily by a great increase in the number of very small infants (Udani, 1963 ), and these form a high proportion of the early deaths. Growth is slow and the menarche may be delayed by malnourishment, occurring at a greater age and greater height but at the same body-weight as in well-nourished girls (Frisch, 1972). Gopalan \& Naidu (1972) related these findings to the consumption of diets which, though suitable for adult maintenance, were inadequate for early growth and development. Weight, rather than age, appeared to be the important factor in the onset of puberty in the rat (Kennedy $\&$ Mitra, 1963), and results shown in Fig. 2 suggest a similar situation amongst the females of colony A.

When adult, the malnourished rats were found to have a greater difference in bodyweight than in body length when compared with well-nourished rats. However, during the period of rapid growth (up to 3 months) the retardation is similar so that malnourished animals have a physique similar to that of younger well-nourished animals. This is similar to the nutritional dwarfism described in children by Waterlow \& Alleyne (197r). 
Tremors have been reported in malnourished children (Wayburne, 1968; Agrawal \& Katiyar, 1972) and in those recovering from malnutrition (Kahn, 1954). These signs, which were found in one out of 300 cases (Wayburne, I968), may be due, as in the experimental animals, to interference in dendritic development: Dickerson has shown a deficit in gangliosides, thought to be concerned in dendritic function, in malnourished animals (Merat \& Dickerson, I974) and children dying of malnutrition (J. W. T. Dickerson, personal communication).

There are many reports that children of low birth weight as well as those undernourished postnatally perform less well at school than well-nourished subjects with similar ethnic and environmental backgrounds (see review by Platt \& Stewart, 1971). Fitzhardinge \& Steven (1972) reported that in a series of SFGA (full-term) infants a higher than usual proportion had convulsions, hyperactivity, short attention spans, learning difficulties, poor co-ordination and hyper-reflexia. There was also an increased proportion showing mild diffuse changes in the electroencephalograms, speech defects, immaturity of reception and expression and a poor school performance. Boys were more often affected than girls, but as in so many other reports, it is difficult to exclude non-nutritional environmental factors. Recent reports from Jamaica (Hertzig, Birch, Richardson \& Tizard, 1972; Richardson, Birch, Grabie \& Yoder, 1972), in which children hospitalized for severe malnutrition before reaching 2 years of age were compared with siblings as well as 'age' controls, suggest that during school life such children may be expected to have defects in full-scale, verbal and performance intelligence quotients. They are also less attentive, less controllable and less well regarded than their peers.

It is not only children of the severely deprived communities which are affected, for similar trends can be found amongst low-birth-weight children, especially those in low socio-economic groups, in well-developed countries (Drillien, I964, I969; Wiener, 1968). All SFGA children are not the result of a poor maternal diet, but it is important to recognize that any factor, e.g. infection, illness, placental insufficiency or smoking, which restricts the flow and return of nutrients and waste products from mother to child may produce an intra-uterine malnutrition.

Long-continued marginal PED results, in both human and animal communities, in modifications in birth weight, bone size, growth, adult stature, sexual maturation, behaviour, learning patterns, endocrine systems (Heard \& Stewart, 197I) and carbohydrate metabolism (Heard, r966). As there are so many similarities, the colony of malnourished rats is recommended as a suitable model on which to study reproductive efficiency, the processes and problems of rehabilitation, as well as those causative factors which can act both pre- and postnatally, whose effects are modified by diet and training and, although susceptible to temporary exacerbation or inhibition, cannot be altered fundamentally after the completion of the brain growth spurt. 


\section{REFERENCES}

Agrawal, S. P. \& Katiyar, G. P. (1972). Pediat. Clins India 7, 203.

Antonov, A. N. (1947). F. Pediat. 30, 250.

Chandran, K. \& Ambegaokar, S. D. (1959). Indian f. med. Res. 47, 539.

Chow, B. F. \& Lee, C-J. (1964). F. Nutr. 82, Io.

Cragg, B. G. (1972). Brain 95, I43.

Dobbing, J. (1974). In Scientific Foundations of Paediatrics p. 565 [J. A. Davis and J. Dobbing, editors]. London: Heinemann Medical Books.

Dobbing, J. \& Sands, J. (1973). Archs Dis. Childh. 48, 757.

Drillien, C. M. (1964). The Growth and Development of the Prematurely Born Infant. Edinburgh, London: E \& S Livingstone Ltd.

Drillien, C. M. (1969). Archs Dis. Childh. 44, 562.

Eayrs, J. T. \& Horn, G. (1955). Anat. Rec, 121, 53.

Fitzhardinge, P. M. \& Steven, E. M. (I972). Pediatrics, Springfield 50, 50.

Frisch, R. E. (1972). Pediatrics, Springfield 50, 445.

Gopalan, C. \& Naidu, A. N. (1972). Lancet ii, 1077.

Gupta, S. R. (1969). Indian F. med. Res. 57, 359.

Gupta, S. R. \& Christie, B. (1968). Indian Y. med. Res. 56, I 14.

Heard, C. R. C. (1966). Diabetes 15, 78.

Heard, C. R. C. \& Stewart, R. J. C. (197I). Hormones 2, 40.

Hertzig, M. E., Birch, H. G., Richardson, S. A. \& Tizard, J. (1972). Y. Pediat. 49, 814.

Kahn, E. (1954). Archs Dis. Childh. 29, 256.

Kennedy, G. C. \& Mitra, J. (r963). Y. Physiol., Lond. 166, 408.

Lashley, K. S. (1938). F. gen. Psychol. 18, 123.

Merat, A. \& Dickerson, J. W. T. (I974). Biol. Neonat. 25, I 58.

Milam, D. F. \& Darby, W. J. (1945). Sth. med. Y., Nashville 38, I 7 .

Naismith, D. J. (1969). Proc. Nutr. Soc. 28, 25.

Naismith, D. J. \& Ritchie, C. (1973). Proc. Nutr. Soc. 32, IA.

Payne, P. R. \& Stewart, R. J. C. (1972). Lab. Anim. 6, I35.

Platt, B. S., Miller, D. S. \& Payne, P. R. (196r). In Recent Advances in Human Nutrition p. $35 \mathrm{I}$ [J. F. Brock, editor]. London: J. \& A. Churchill.

Platt, B. S. \& Stewart, R. J. C. (1968). Devl Med. Child Neurol. ro, 3.

Platt, B. S. \& Stewart, R. J. C. (1969). Devl Med. Child Neurol. I1, 174.

Platt, B. S. \& Stewart, R. J. C. (1971). Wld Rev. Nutr. Diet. 13, 43.

Richardson, S. A., Birch, H. G., Grabie, E. \& Yoder, K. (I972). F. Hlth Soc. Behav. 13, 276.

Scrimshaw, N. S. (1964). In Mammalian Protein Metabolism Vol. 2, p. 569 [H. N. Munro and J. B. Allison, editors]. New York, London: Academic Press.

Smith, C. A. (1947). F. Pediat. 30, 229.

Stewart, R. J. C. (1965). Wld Rev. Nutr. Diet. 5, 275.

Stewart, R. J. C. (1972). Pan-Am. Hlth Orgn scient. Publs no. 25 I, 33.

Stewart, R. J. C. (1973). Nutr. Rep. Int. 7,487.

Stewart, R. J. C., Merat, A. \& Dickerson, J. W. T. (1974). Biol. Neonat. 25, 25.

Stewart, R. J. C., Preece, R. F. \& Sheppard, H. G. (1973a). Proc. Nutr. Soc. 32, 102 A.

Stewart, R. J. C., Preece, R. F. \& Sheppard, H. G. (1973b). Proc. Nutr. Soc. 32, 103 A.

Stewart, R. J. C. \& Sheppard, H. G. (I971). Br. F. Nutr. 25, I75.

Turkewitz, G. (1974). Proc. Kittay Foundation Symp. (In the Press.)

Udani, P. M. (1963). Indian Y. Child Hlth 12, 593.

Waterlow, J. C. \& Alleyne, G. A. O. (197I). In Advances in Protein Chemistry Vol. 25, p. 117 [C. B. Anfinsen, J. T. Edsell and F. M. Richards, editors]. New York and London: Academic Press Inc.

Wayburne, S. (I 668). In Calorie Deficiencies and Protein Deficiencies p. 7 [R. A. McCance and E. M. Widdowson, editors]. London: J. \& A. Churchill.

Wiener, G. (1968). F. spec. Educ. 2, 237.

\section{EXPLANATION OF PLATES}

\section{Plate I}

Young rats from colonies maintained for twelve generations on diets of different protein value, showing great retardation of growth: $(a) 42$-d-old rat from colony A (diet of low protein value; dietary-protein energy : total metabolizable energy (NDp:E) 0.068 ); (b) r2-d-old rat from colony B (diet of high protein value; NDp: $\mathrm{E} 0.10)$; $(c) 42$-d-old rat from colony $\mathrm{B}$. Note that $(a)$ and $(b)$ are of equal body-weight, and $(a)$ and $(c)$ are of equal age. 


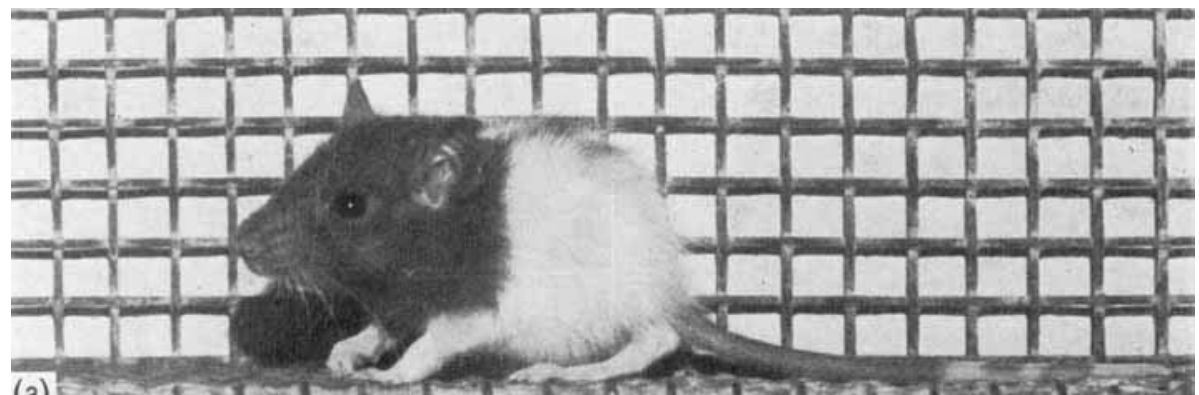

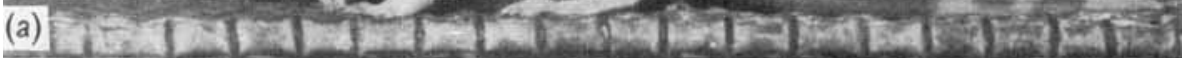
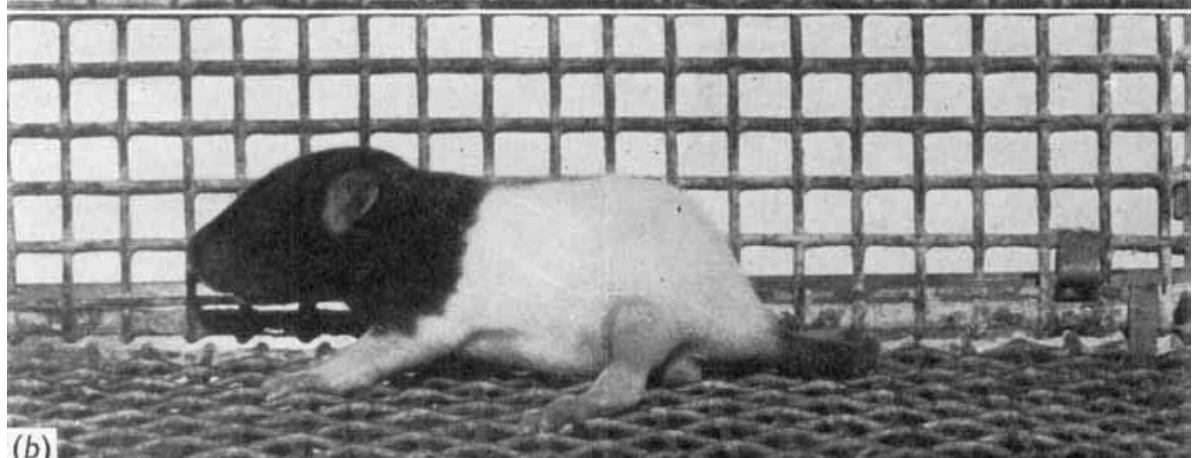

(b)

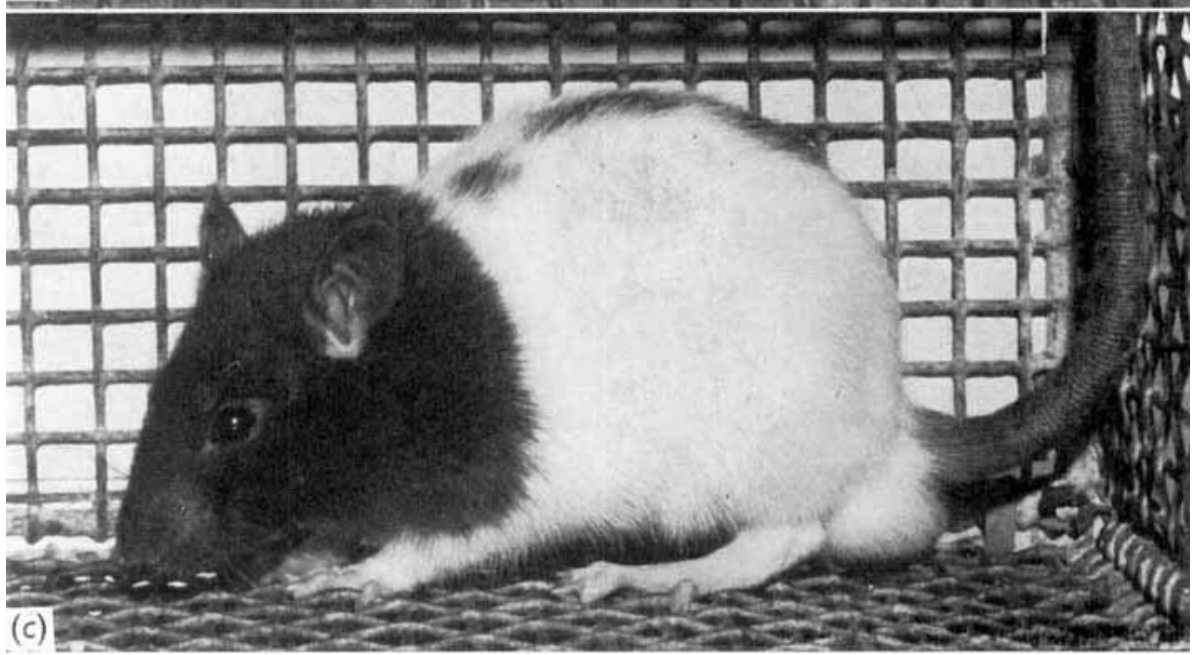


British fournal of Nutrition, Vol. 33, No. 2

Plate 2
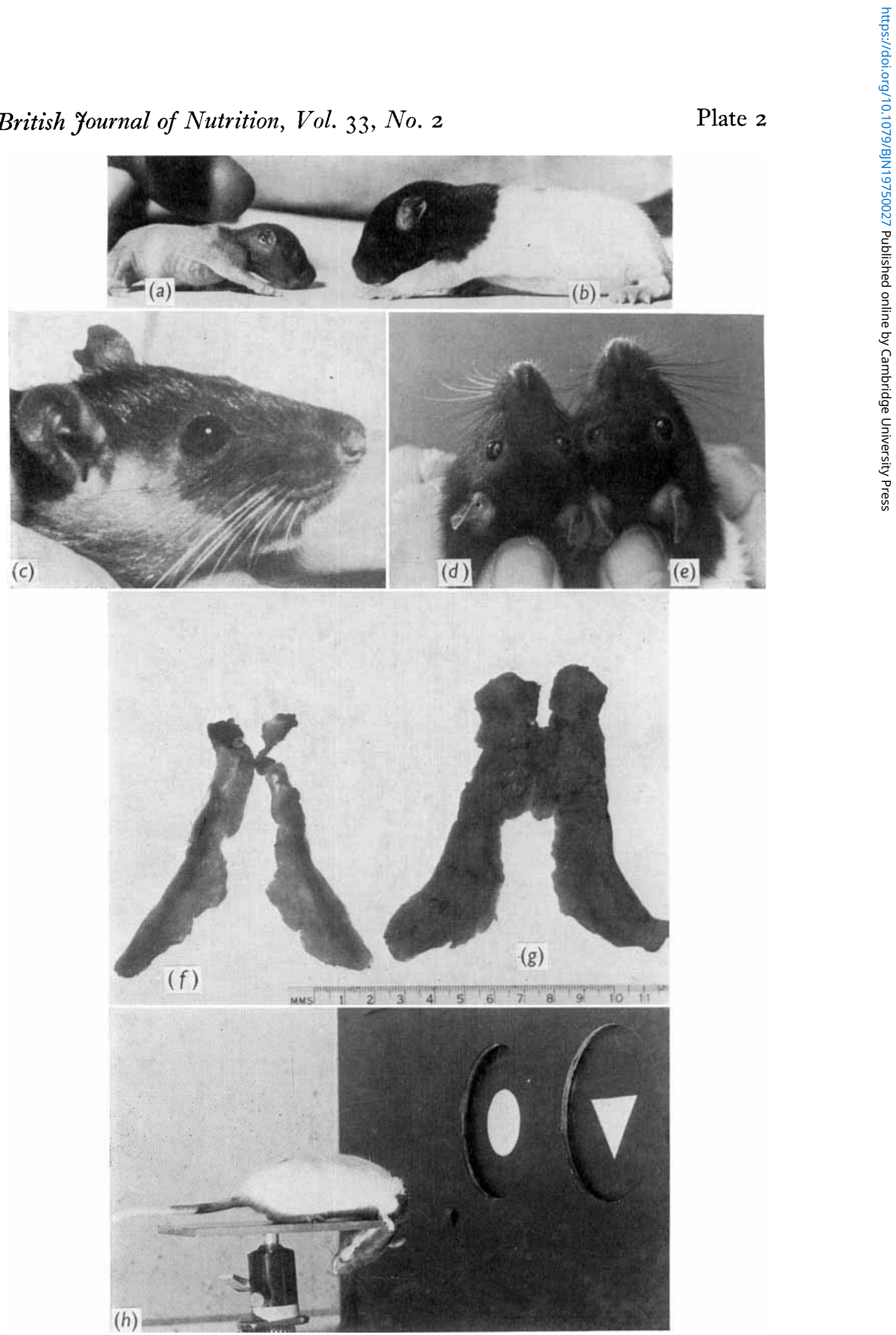

R. J. C. STEWART, R. F. PREECE AND HILDA G. SHEPPARD 


\section{Plate 2}

The differences in hair, head shape, mammary glands and behaviour in rats from colonies maintained for twelve generations on diets of high $(b, e, g)$ and low $(a, c, d, f, h)$ protein values (dietary-protein energy: total metabolizable energy $0 \cdot 10$ and 0.068 respectively) are shown. $(a)$ and $(b)$ I0-d-old rats; note the small size and poor hair development in the malnourished animal $(a) ;(c)$ loss of hair caused by contact with food hoppers; $(d)$ and $(e) 6$-month-old rats; note the great difference in length of nose and similarity in eye and cranial size; $(f)$ and $(g)$ posterior mammary glands from rats 4 weeks after parturition and $3 \mathrm{~h}$ after removal from the young; $(h)$ rat from the malnourished colony still trying to climb down and thereby avoid a decision after having fallen twenty-three times. This rat had already passed tests 1 and 2 (see Lashley, 1938). 